\title{
Autologous Dendritic Cell-Tumor Fusion Vaccine
}

National Cancer Institute

\section{Source}

National Cancer Institute. Autologous Dendritic Cell-Tumor Fusion Vaccine. NCI

Thesaurus. Code C74016.

A therapeutic cancer vaccine consisting of autologous dendritic cells (DCs) fused with autologous tumor cells with potential immunostimulatory and antineoplastic activities. Autologous dendritic cell-tumor fusion vaccine is generated in vitro by mixing DCs and irradiated tumor cells harvested from individual patients and treating them with polyethylene glycol (PEG) to produce DC-tumor cell fusion hybrid cells. Upon administration, autologous dendritic cell-tumor fusion vaccine may elicit antitumor humoral and cellular immune responses. 